\title{
Teacher Team Effectiveness and Teachers Well-being
}

\author{
Christian Jacobsson ${ }^{*}$, Maria Ákerlund, Elisabet Graci, Emma Cedstrand and Trevor Archer \\ Department of Psychology, University of Gothenburg, Sweden \\ *Corresponding author: Christian Jacobsson, Department of Psychology, University of Gothenburg, Sweden, Tel: +46708431266; E-mail: \\ christian.jacobsson@psy.gu.se
}

Received date: June 07, 2016; Accepted date: June 14, 2016; Published date: June 21, 2016

Copyright: (c) 2016 Jacobsson C, et al. This is an open-access article distributed under the terms of the Creative Commons Attribution License, which permits unrestricted use, distribution and reproduction in any medium, provided the original author and source are credited.

\begin{abstract}
The purpose of the present study was to examine the relationship between how teachers rate the effectiveness of their 'teacher-teams' as well as the experience of their own well-being. Team effectiveness was measured using the Group Development Questionnaire and well-being was assessed through responses on scales derived for estimating emotional exhaustion and work satisfaction. Data were collected from 521 Swedish teachers and preschool teachers belonging to 105 teacher-teams, the response rate was $100 \%$. The results indicate a strong relationship between the effectiveness of the teacher-teams and teachers' well-being, both with regard to levels of emotional exhaustion and work satisfaction. More effective teamwork was associated with lower levels of emotional exhaustion and higher levels of work satisfaction. The practical implications of these observations are discussed with regard to future research.
\end{abstract}

Keywords: Teacher team effectiveness; Well-being; Emotional exhaustion; Work satisfaction

\section{Introduction}

Team-based work as an organizational structure in schools and preschools is widespread internationally and currently presents the standard syllabus in Sweden. Nevertheless, team-based work may be more or less effective. There is substantial support for the link between effectiveness of cooperation in teams and task-related results such as goal attainment in general [1,2]. Regarding schools, Wheelan and colleagues $[3,4]$ found a link between how effective teacher teams cooperates and their pupils' performance on standardized tests, the better cooperation among teachers - the higher performance among pupils. Thus, the quality of cooperation among teacher teams exerts a significant influence with regard to outcome measures, such as pupils performance, in schools as well as in other industries. This study will address another important topic connected to teacher teams, the relationship between teacher team effectiveness and teachers' wellbeing. By teacher team effectiveness we mean to what degree the teams could be described as effective in their cooperation, e.g. having shared goals and clear roles.

Teaching is generally considered a stressful occupation [5,6]. For instance, according to the national social insurance agency in Sweden [7] teachers have a high relative risk for sleeping disorders and also sick-absenteeism due to psychiatric diagnoses such as burnout. Thus, well-being, which implies the positive condition of an individual or a group, entails a necessary ingredient within this context.

The main purpose of this study was to examine the relationship between teacher-team effectiveness and members' levels of emotional exhaustion and work satisfaction as signs of well-being. Emotional exhaustion, a chronic state of physical and emotional depletion accruing from excessive job and/or personal demands and continuous sometimes referred to as 'burnout' [8], is part of the Common Mental Disorders [9], thereby posing an ever-increasing area of concern for society. With regard to both individuals' health and social costs, efforts eliminate emotional exhaustion are necessary. Ancilliary to the main purpose it was deemed important to ascertain whether or the findings of the present study may fit with those of an earlier study wherein the same research design in a different organizational setting, manufacturing industry was employed [10].

The relationship between the quality of team work and team members well-being has been relatively in schools and pre-schools although not in other occupations [11]. Kivimäki et al. [12] found that poor team climate is associated with depressive disorders in a nationally representative sample [13] and absence due to sickness of hospital physicians [12]. So et al. [14] showed that quality of team work was associated significantly with greater employee satisfaction and lower stress in the health services. Finally, Jacobsson et al. [10] found that effectiveness of team work was positively related to work satisfaction and negatively related to emotional exhaustion for team members in manufacturing industry.

\section{Teacher Team Effectiveness}

This study uses the Integrated Model of Group Development (IMGD) and the linked instrument Group Development Questionnaire (GDQ) [3] as a way of describing and measuring team effectiveness. The integrated model is an integration of earlier theory and research on group development across time [15-19]. The validity of the IMGD and GDQ has been established in a number of studies [20-23]. IMGD is a model describing four stages of group development. The stages in are (I) dependency and inclusion, (II) counter-dependency and fight, (III) trust and structure, and (IV) work and productivity.

The first stage is characterized by team member dependency on the leader, safety concerns, and inclusion issues. The second stage is distinguished by team members having opposing perspectives, counter-dependency toward the leader, and tensions in the team. The third stage is marked by increased trust and focus on finding better structure and strategies for goal achievement in the team. Finally, the fourth stage is characterized by the intense focus of team members on 
Page 2 of 5

achieving the goal(s). Stage IV groups have also established a team climate of openness and cohesion that facilitates effective work. Stage I groups spend about $40 \%$ working effectively and Stage IV groups about $80 \%$. The remaining time is used for maintenance, and dealing with interpersonal issues that arise and the like [23]. Available data on distribution across stages based on 764 groups' representative of Swedish working life shows that $29 \%$ are in stage I, $21 \%$ in stage II, $30 \%$ in stage III and $20 \%$ in stage IV [24]. Teams in schools and preschools seems to be comparatively well functioning, $20 \%$ are in stage I, $17 \%$ in stage II, $34 \%$ in stage III and $29 \%$ in stage IV [24].

\section{Emotional exhaustion and work satisfaction}

In the present study, we have chosen to investigate two well-being related aspects of working life, emotional exhaustion and work satisfaction.

According to Maslach, emotional exhaustion is considered to be the key component of burnout $[25,26]$. In a longitudinal study of predictors of burnout among teachers, Burke and Greenglass [27] found that both the role stressors of conflict and ambiguity, and lack of social support were predictors of emotional exhaustion. Not only for teachers but in general, lack of support from the leader and from colleagues is associated with burnt out $[28,29]$. Effective teams are characterized by the opposite; they are unambiguous and supportive. High participation in decision making is another key feature of effective team work. Likewise, low degree of participation is associated with burnout. Similar to participation, low degree of control is also associated with stress related problems [28]. Jacobsson and Pousette [30] found that teachers who coordinated their work with others by common goals, as effective teams does, had lower levels of burnout than teachers who were working more alone and focused on coordinating their own work. On the basis of literature, the following hypothesis was formulated.

Hypotheseis 1: The more effective the team work, the lower the levels of emotional exhaustion among teachers

Teachers' work satisfaction is important because it influences teachers' performance and wellbeing $[31,32]$. Some of these conditions that correlate with work satisfaction are constructs that are characteristics of more or less developed groups. For instance, Roberson [33] found a relation between goal clarity, which is an aspect of effective teamwork, and work satisfaction. Parker et al. [34] found in their meta-analytic review a positive correlation of 0.48 between a general appreciation of an individual's work group and work satisfaction. Based on this research, we formulated the second hypothesis.

Hypotheseis 2: The more effective the team work, the higher the levels of work satisfaction amomg teachers

\section{Method}

\section{Participants and procedure}

This study included teams in pre-schools and comprehensive schools in a municipally controlled school district and was carried out using a questionnaire. The questionnaire was distributed to team members during working hours on their regular work-meetings. The study covered all team members, belonging to 105 teams, the response rate was $100 \%, \mathrm{n}=521$ respondents. 66 of the team worked in preschools and 39 in schools. The number of team member varied between 3 and 11, with an average of 5.0 team members/team. The teams in pre-schools were smaller in size $(\mathrm{M}=4.2$ members) than teams in schools ( $M=6.2$ members). Gender and age was not examined, however schools and especially pre-schools are markedly female dominated. The age of the teams, how long they had been working together varied much, from 1 month to 192 months (16 years). On average, the teams had been working together for 20.2 months, somewhat shorter time in schools $(M=18.1)$ than in pre-schools (21.5). The team age was calculated from the starting point, how long at least $50 \%$ of the members had worked together in the same team.

\section{Measures}

Teacher team effectiveness: Group development Questionnaire, GDQ [21], was used for assessing effectiveness of the teams. The 60item GDQ contains four scales that correspond to the four stages of group development according to IMGD. Each scale contains 15 items and each item has a Likert-type response scale from 1 (never true of this group) to 5 (always true of this group). Therefore, the minimum score on each scale is 15 and the maximum score is 75 . This study was conducted with the Swedish translation of GDQ, GDQ SE3. Cronbach's alphas for GDQ SE3 Scales 1, 2, 3 and 4 are 0.77, 0.90, 0.81, and 0.87, respectively [35]. Sample items for the GDQ is shown in Table 1 and norm data for GDQ SE3 are shown in Table 2. Norms are based on 764 groups that were representative for Swedish working life.

\begin{tabular}{|l|l|}
\hline \multicolumn{1}{|c|}{ GDQ scale } & \multicolumn{1}{|c|}{ Sample items } \\
\hline GDQ 1 & $\begin{array}{l}\text { Members tend to go along with whatever the leader suggests. } \\
\text { There is very little conflict expressed in the group. } \\
\text { We haven't discussed our goals very much. }\end{array}$ \\
\hline GDQ 2 & $\begin{array}{l}\text { People seem to have very different views about how things should be done in this group. } \\
\text { Members challenge the leader's ideas. } \\
\text { There is quite a bit of tension in the group at this time. }\end{array}$ \\
\hline GDQ 3 & $\begin{array}{l}\text { The group is spending its time planning how it will get its work done. } \\
\text { We can rely on each other. We work as a team. } \\
\text { The group is able to form subgroups, or subcommittees, to work on specific tasks. }\end{array}$ \\
\hline GDQ 4 & The group gets, gives, and uses feedback about its effectiveness and productivity. \\
\hline
\end{tabular}




\begin{tabular}{|l|l|}
\hline & $\begin{array}{l}\text { The group acts on its decisions. } \\
\text { This group encourages high performance and quality work. }\end{array}$ \\
\hline
\end{tabular}

Table 1: Sample items for GDQ.

\begin{tabular}{|l|l|l|l|l|}
\hline & Scale 1 & Scale 2 & Scale 3 & Scale 4 \\
\hline Max. value & 52.8 & 62.3 & 74.0 & 72.2 \\
\hline 84 percentile & 43.5 & 43.5 & 59.5 & 61.1 \\
\hline Mean. value & 37.7 & 34.8 & 53.2 & 54.7 \\
\hline 16 percentile & 31.8 & 26.1 & 46.9 & 48.3 \\
\hline Min. value & 20.3 & 16.0 & 30.0 & 30.0 \\
\hline Stand. dev. & 5.8 & 8.6 & 6.3 & 6.3 \\
\hline
\end{tabular}

Table 2: Norms for GDQ SE3 based on 764 Swedish groups.

A group's overall stage is determined by considering the mean scores of the four scales for a specific group and comparing them with mean scores of normative data. During Stage I of group development, the mean score on GDQ Scale 1 is at its highest, and scores on the other three scales are relatively low. During Stage II, the mean score of GDQ Scale 2 is at its highest, and scores on the other three scales remain relatively low. At Stage III, mean scores on GDQ Scales 3 and 4 begin to increase, and mean scores on GDQ Scales 1 and 2 remain relatively low. Finally, at Stage IV, mean scores on GDQ Scales 3 and 4 continue to increase, whereas mean scores on GDQ Scales 1 and 2 remain relatively low [36]. To summarize, groups with a low degree of development have high values on Scales 1 and 2 but low values on Scales 3 and 4. Groups with a high degree of development (i.e., being effective team) have the opposite, low values on scales 1 and 2 but high values on Scales 3 and 4.

Emotional exhaustion: It was measured with the personal burnout subscale of the Copenhagen Burnout Inventory [37]. However, after having a response-psychological test-panel use the scale in an earlier study, it was reduced from six to five items [30]. The excluded item was about feeling receptive to sickness and was difficult to answer. Of the remaining five items, example items are as follows: "How often do you feel tired?" and "How often are you emotionally exhausted?" Scale responses range from 1 (never) to 5 (always); Cronbach's alpha was 0.88 according to Jacobsson and Pousette [30].

Work satisfaction: Job satisfaction was measured with a three-item scale of overall job satisfaction [38]. Sample items are "Based on an overall assessment, how satisfied are you with your current work situation?" and "How well does your company meet your expectations for how you want it in your work?" The scale responses range from 1 (not at all) to 10 (to the highest degree). Cronbach's alpha was 0.91 [30].

\section{Statistical analysis}

Pearsons' product-moment correlations were calculated in order to analyze inter-correlations. All analyses were made on group-level, based on mean-values for the 105 teams included, two-tailed tests were used.

\section{Results}

Means (and standard deviations) for the 105 teams on GDQ scales were for GDQ scale $1 ; \mathrm{M}=34.5$ ( $\mathrm{SD}=6.9)$, for scale $2 ; \mathrm{M}=31.0(\mathrm{SD}=8.7)$, for scale $3 ; \mathrm{M}=56.8(\mathrm{SD}=6.4)$, and for scale $4 ; \mathrm{M}=57.8(\mathrm{SD}=6.0)$. Means (and standard deviations) for emotional exhaustion was; $\mathrm{M}=2.8$ ( $\mathrm{SD}=0.5)$, for work satisfaction; $\mathrm{M}=5.7(\mathrm{SD}=1.4)$.

GDQ-scale 1 and 2 were below the mean compared with Swedish GDQ norms and the means of GDQ-scale 3 and 4 were above the Swedish GDQ norms presented in Table 2. The mean values of the 105 teams in the present study compared to Swedish norms, indicate that the studied teams were somewhat more developed, more effective working, as groups than the average Swedish team. Mean values for emotional exhaustion and work satisfaction were at the same levels as available reference data on Swedish employees [30].

The results presented in Table 3 provide support for hypothesis 1, as expected, that less signs of emotional exhaustion among group members should be shown when the team is more effective working together. The effect sizes were moderately strong, according to Cohen [39]. The strongest relationship was between GDQ scale 3, trust and structure, and emotional exhaustion. The results also gave support to hypothesis 2, that more effective team work is associated with higher levels of work satisfaction. All four correlations were significant and in the same direction as the hypothesis, with effect sizes that were moderately strong to strong, according to [39]. The strongest correlation was between scale 4 , the occurrence of effective and goaldirected cooperation in the team, and work satisfaction. 
Page 4 of 5

\begin{tabular}{|l|l|l|l|l|}
\hline & Scale 1 & Scale 2 & Scale 3 & Scale 4 \\
\hline Emotional exhaustion & $0.31^{* \star}$ & $0.38^{* *}$ & $-0.41^{* *}$ & $-0.36^{*}$ \\
\hline Work satisfaction & $-0.20^{*}$ & $-0.26^{* *}$ & $0.42^{* *}$ & $0.46^{* *}$ \\
\hline
\end{tabular}

Table 3: Correlations between GDQ scales $1-4$ and work satisfaction and emotional exhaustion, $\mathrm{N}=105$ teams. ${ }^{*}$ Correlation is significant at the 0.01 level ${ }^{\star}$ Correlation is significant at the 0.05 level.

\section{Discussion}

The purpose of the present study was to examine the relationship between teacher team effectiveness and teachers' well-being with regard to emotional exhaustion and work satisfaction using a research design employed previously. The main findings indicated a straightforward link between team effectiveness, as estimated by the GDQ, both and emotional exhaustion and work satisfaction. Thus, the association between the quality of team work and team members' experience of well-being was evidenced. These findings are supported by those of a previous one performed within the manufacturing industry [10].

Hypothesis 1: That effective team work is negatively correlated with emotional exhaustion was confirmed. There were significant correlations with all four scales of the GDQ and the effect sizes were medium strong to strong [39]. The correlation of 0.38 between scale 2 and emotional exhaustion implies that the greater the conflict dynamics in teacher teams, the greater the extent of emotional exhaustion among teachers thereby confirming the link between team work quality and emotional exhaustion/stress from previous findings $[6,14]$. Compared to the earlier study with the same research design [10], the effect sizes were generally smaller with regard to emotional exhaustion in manufacturing industry. These estimations imply that effectiveness of team work was more important with regard to emotional exhaustion in schools and pre-schools than in manufacturing industry.

Hypothesis 2: That effective team work is positively correlated with work satisfaction was confirmed. We found significant correlations with all four scales of the GDQ, with effect sizes that were moderately strong to strong, according to Cohen [39]. The strongest relationship was between GDQ scale 4 and work satisfaction, the more effective the team, the higher the levels of work satisfaction. This result is consistent with earlier findings with regard to employees in the health services [14]. Compared to the other study with the same research design [10], the effect sizes were generally stronger in manufacturing industry. For instance, the correlation between GDQ scale 4 and work satisfaction in manufacturing industry was 0.68 , compared to 0.46 in the current study. This implies that even though effectiveness of team work is important with regard to work satisfaction in schools and pre-schools, it is less important than in manufacturing industry.

The present study was limited by its' cross-sectional design with data from one municipally controlled school district. Despite not being specifically tested for, it is possible that teacher team effectiveness and emotional exhaustion mutually reinforce each other, at least to some degree. An interesting topic for future research should be designing a longitudinal study that offer more of causal explanations of the links between teacher team effectiveness, emotional exhaustion and work satisfaction. An intervention study wherein interventions are focused on teacher team development may be preferable, and besides this also measures of emotional exhaustion and work satisfaction across time.
Even though there is only one sample from one school district in the present study, there are reasons to believe the results are persistent since they are replicated in a different organizational setting [10].

Earlier research has pointed out the link between teacher team effectiveness and pupils achievements $[3,4,40]$. The major finding here is the link between teacher team effectiveness and teacher well-being. Effective team work is associated with low levels of emotional exhaustion, a part of Common Mental Disorders, and high levels of work satisfaction. A practical implication is the prospect that team development is a relevant focus area, not only for enhancing team effectiveness, but also enhancing teacher well-being and decreasing Common Mental Disorder within occupational situations.

\section{Conclusions}

The present study examined teacher team effectiveness and its relation to two aspects of well-being: work satisfaction and emotional exhaustion. The results indicated that members of effective teacher teams show higher levels of work satisfaction and lower levels of emotional exhaustion. These results imply that membership of an effective team may promote health and psychological well-being among teachers.

\section{Disclosure Statement}

No potential conflict of interest was reported by the authors.

\section{References}

1. Naumann SE, Bennett N (2002) The Effects of Procedural Justice Climate on Work Group Performance. Small Group Research 33: 361-377.

2. Wallace C, Gilad C (2006) A Multilevel Integration of Personality, Climate, Self-Regulation, and Performance. Personnel Psychology 59: 529-557.

3. Wheelan SA, Kesselring J (2005) The Link Between Faculty Group Development and Elementary Student Performance on Standardized Tests. The Journal of Educational Research 98: 223-230.

4. Wheelan SA, Tilin F (1999) The Relationship between Faculty Group Development and School Productivity. Small Group Research 30: 59-81.

5. Chaplain RP (2008) Stress and psychological distress among trainee secondary teachers in England. Educational Psychology 28: 195-209.

6. Jacobsson C, Pousette A (2001) Coordinating work in Swedish schools. Journal of Educational Administration 39: 147-161.

7. Försäkringskassan (2014) Sjukfrånvaro i psykiska diagnoser (Sickabsenteeism in psychiatric diagnoses) Socialförsäkringsrapport (Social Insurance Report).

8. Wright TA, Cropanzano R (1998) Emotional exhaustion as a predictor of job performance and voluntary turnover. J Appl Psychol 83: 486-93.

9. Krueger RF (1999) The structure of common mental disorders. Arch Gen Psychiatry 56: 921-6. 
10. Jacobsson C, Rydbo N, Börresen JE (2014) The Links Between Group Development and Health in Manufacturing Industry. Small Group Research 45: 400-415.

11. Wright TA, Cropanzano R, Bonett DG (2007) The moderating role of employee positive well being on the relation between job satisfaction and job performance. J Occup Health Psychol 12: 93-104.

12. Kivimäki M, Sutinen R, Elovainio M, Vahtera J, Räsänen K, et al. (2001) Sickness absence in hospital physicians: 2 year follow up study on determinants. Occupational and Environmental Medicine 58: 361-366.

13. Sinokki M, Hinkka K, Ahola K, Koskinen S, Klaukka T, et al. (2009) The association between team climate at work and mental health in the Finnish Health 2000 Study. Occupational and Environmental Medicine 66: 523-528.

14. So TTC, West MA, Dawson JF (2011) Team-based working and employee wellbeing: A cross-cultural comparison of United Kingdom and Hong Kong health services. European Journal of Work and Organizational Psychology 20: 305-325.

15. Bales RF (1965) The Equilibrium Problem in Small Groups.

16. Bales RF, Strodtbeck FL (1951) Phases in group problem-solving. The Journal of Abnormal and Social Psychology 46: 485-495.

17. Bennis WG, Shepard HA (1956) A theory of group development. Human Relations 9: 415-437.

18. Bion WR (1961) Experiences in Groups. London: Tavistock.

19. Tuckman BW, Jensen MAC (1977) Stages in Small Group Development Revisited. Group and Organization Management 2: 419-438.

20. Wheelan SA, Davidson B, Tilin F (2003) Group Development Across Time: Reality or Illusion?. Small Group Research 34: 223-241.

21. Wheelan SA, Hochberger JM (1996) Validation Studies of the Group Development Questionnaire. Small Group Research 27: 143-170.

22. Wheelan SA, Mckeage RL (1993) Developmental Patterns in Small and Large Groups. Small Group Research 24: 60-83.

23. Wheelan SA, Williams T (2003) Mapping Dynamic Interaction Patterns in Work Groups. Small Group Research 34: 443-467.

24. Wheelan SA, Jacobsson C (2014) A Descriptive Study of Work Groups in the Swedish and US Economy.

25. Alharbi J, Wilson R, Woods C, Usher K (2016) The factors influencing burnout and job satisfaction among critical care nurses: a study of Saudi critical care nurses. J Nurs Manag.

26. Maslach C, Jackson SE (1981) The measurement of experienced burnout. Journal of Organizational Behavior 2: 99-113.
27. Burke RJ, Greenglass E (1995) A Longitudinal Study of Psychological Burnout in Teachers. Human Relations 48: 187-202.

28. Nieuwenhuijsen K, Bruinvels D, Frings-Dresen M (2010) Psychosocial work environment and stress-related disorders, a systematic review. Occupational Medicine 60: 277-286.

29. SBU (2014) Arbetsmiljöns betydelse för symtom på depression och utmattningssyndrom [Working Environment significance for symptoms of depression and burnout]: Statens beredning för medicinsk utvärdering [Swedish Council on Health Technology Assessment].

30. Jacobsson C, Pousette A (2012) Psykosocial arbetsmiljö i vård och omsorg - Bakgrund till Indikators medarbetarenkät [Psychosocial work environment in health care sector- background to Indikators employee survey]. Institutet för kvalitetsindikatorer. Gothenburg, Sweden.

31. Caprara GV, Barbaranelli C, Borgogni L, Steca P (2003) Efficacy Beliefs as Determinants of Teachers' Job Satisfaction. Journal of Educational Psychology 95: 821-832.

32. Klassen RM (2010) Teacher Stress: The Mediating Role of Collective Efficacy Beliefs. Journal of Educational Research 103: 342-350.

33. Roberson L (1990) Prediction of job satisfaction from characteristics of personal work goals. Journal of Organizational Behavior 11: 29-41.

34. Parker CP, Baltes BB, Young SA, Huff JW, Altmann RA, et al. (2003) Relationships between psychological climate perceptions and work outcomes: A meta-analytic review. Journal of Organizational Behavior 24: 389-416.

35. Jacobsson C, Pousette A, Thylefors I (2001) Managing Stress and Feelings of Mastery among Swedish Comprehensive School Teachers. Scandinavian Journal of Educational Research 45: 37-53.

36. Wheelan SA (2005) Group processes: A developmental perspective. Boston: Allyn \& Bacon.

37. Kristensen TS, Borritz M, Villadsen E, Christensen KB (2005) The Copenhagen Burnout Inventory: A new tool for the assessment of burnout. Work \& Stress 19: 192-207.

38. Wanous JP, Lawler EE (1972) Measurment and meaning of job satisfaction. Journal of Applied Psychology 56: 95-105.

39. Cohen J (1992) A power primer. Psychological Bulletin 112: 155-159.

40. Ronfeldt M, Farmer SO, McQueen K, Grissom JA (2015) Teacher Collaboration in Instructional Teams and Student Achievement. American Educational Research Journal 52: 475-514. 